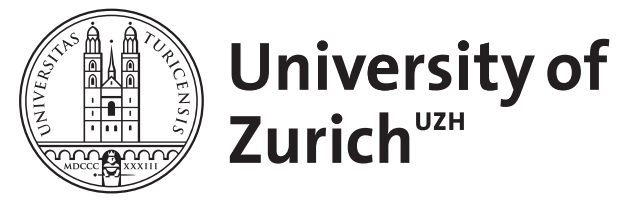

Response to: 'Will SPAR be useful in the usual patients with scleroderma?' by Chattopadhyay et al

\author{
Wu, Wanlong ; Jordan, Suzana ; Distler, Oliver
}

DOI: https://doi.org/10.1136/annrheumdis-2018-214270

Posted at the Zurich Open Repository and Archive, University of Zurich ZORA URL: https://doi.org/10.5167/uzh-158322

Journal Article

Published Version

Originally published at:

Wu, Wanlong; Jordan, Suzana; Distler, Oliver (2019). Response to: 'Will SPAR be useful in the usual patients with scleroderma?' by Chattopadhyay et al. Annals of the Rheumatic Diseases, 78(11):e126e126.

DOI: https://doi.org/10.1136/annrheumdis-2018-214270 


\section{Response to: 'Will SPAR be useful in the usual patients with scleroderma?' by Chattopadhyay et al}

Thank you very much for your interest in our article 'Prediction of progression of interstitial lung disease in patients with systemic sclerosis: the SPAR model ${ }^{1}$ and your precious questions 'Will SPAR be useful in the usual scleroderma patients?'. We are glad to respond as below.

\section{EXTERNAL VALIDITY OF THE STUDY COHORT}

The external validity of the patients recruited is unclear. The authors may like to provide their cohort numbers and how many of them fulfilled the inclusion criteria.

Regarding the question on the external validity of the study cohort, we would like to stress that our study cohort focused on patients with mild interstitial lung disease (ILD) on high resolution computer tompgraph (HRCT), without defining a limit for forced vital capacity (FVC). That is the reason why our patients had an average normal FVC. We disagree that patients with milder ILD and normal FVC are uncommon in clinical practice-please see our recent study. ${ }^{3}$ In fact, many patients with (milder) ILD might be missed if only lung function testing is used for screening.

However, we agree that these patients have not been included in recent interventional clinical trials such as scleroderma lung study (SLS) 1 and 2 which have concentrated on a more severe subpopulation with decreased FVC. Thus, whether the progression of patients with mild systemic sclerosis (SSc)-ILD can be successfully prevented with specific treatments needs to be shown. Notably, the ongoing large randomised placebo controlled SENSCIS trial, which is testing nintedanib versus placebo in patients with SSc-ILD, recruits patients with HRCT involvement $>10 \%$ and no upper limit of FVC. ${ }^{4}$ Thus, post-hoc analysis of this trial in the group of patient with HRCT involvement of 10\%-20\% and 'normal' FVC might partially address this question.

In the derivation cohort (Zurich cohort) to the present study, we have included 397 patients with SSc with complete data, among which 158 patients had ILD. A total of 98 patients $(62 \%)$ fulfilled the inclusion criteria of mild ILD. Base on this result, we assume that the current study cohort represents a large subpopulation of patients with SSc-ILD.

\section{THE STATUS OF ARTHRITIS}

The authors found 'arthritis ever' to be significant after multivariate analysis, though a previous study did not show any association of arthritis and ILD progression. Was baseline presence of arthritis also significant?

Regarding the question on the status of arthritis, the cited study looked at a different study population: this was a mixture of patients with mild and advanced SSc-ILD, follow-up time was longer and a different definition of SSc-ILD progression was used. ${ }^{5}$ Prediction factors for the disease subgroup of more advanced SSc-ILD might be very different from patients with mild SSc-ILD.

The type of arthritis was as follows: only $6.1 \%$ patients ever had erosive arthritis in the derivation cohort, and the presence of anti-cyclic citrullinated peptide (CCP) was low in our cohorts $(3.5 \% \sim 6.5 \%)$. Methotrexate was the most frequently used immunosuppressant $(26.5 \%)$ in our study, but we are unaware whether this was given for the indication of arthritis or for other reasons, for example, skin fibrosis. Current arthritis only showed no significant association with ILD progression in the multivariate analysis, indicating that previous inflammatory disease including arthritis is an important parameter for disease characterisation.

\section{PREDICTIVE PERFORMANCE OF THE SPAR MODEL}

The best multivariate predictive model in this study (model 3: $\mathrm{SpO}_{2} \leq 94 \%+$ arthritis ever) has a sensitivity of only $44 \%$ - thus more than half of the progressors would not be detected.

Regarding the question on the predictive performance of the SPAR model, as shown in table 4 of our paper, ${ }^{1}$ for example, in the derivation cohort, $91.7 \%$ of patients with SPAR score $=2$ actually had ILD progression, 92.6\% of patients with SPAR score $=0$ actually did not have ILD progression. Moreover, $84.0 \%$ of ILD progressors had a SPAR score of 1 or $2,98.6 \%$ of non-progressors had a SPAR score of 0 or 1 . All these results indicate that most ILD progressors $(>80 \%)$ could be identified

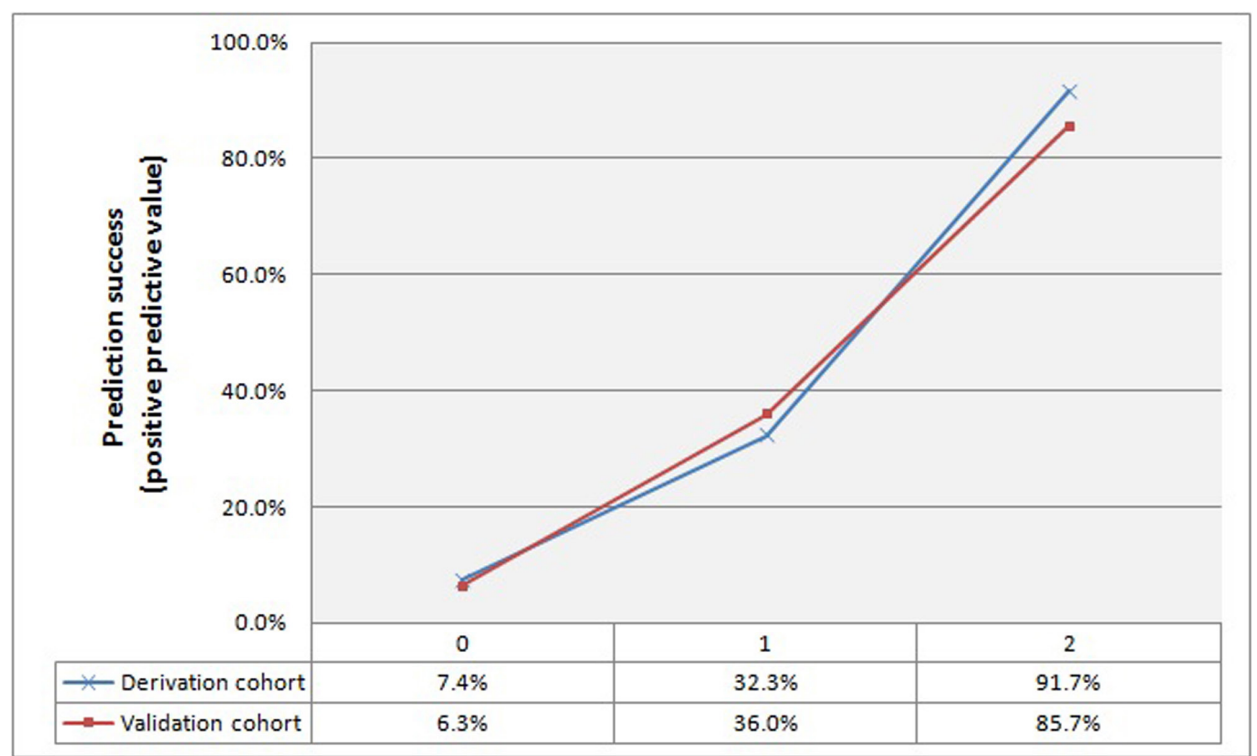

Figure 1 Prediction success rate with SPAR score for progression of mild SSc interstitial lung disease. PPV, positive predictive value. 
when the patients fulfilled either of these two characteristics ( $\mathrm{SpO}$, after 6MWT $\leq 94 \%$, arthritis ever).

Meanwhile, patients with neither of these two characteristics had a really low chance $(<10 \%)$ to have a deterioration of ILD in the next 1 year. This is further highlighted in figure 1 . Thus, although further external validation and testing in clinical practice is still required, we believe that the SPAR model provides a promising risk-stratification tool in patients with mild SSc-ILD.

\section{OTHER POTENTIAL PREDICTORS}

The authors may like to provide any data on other variables expected to predict progression-baseline extent of ILD on CT (varying from $0 \%$ to $20 \%$ ), oesophageal diameter on HRCT and nailfold capillaroscopy.

Regarding the question on other potential predictors, we fully agree that other clinical variables could potentially predict ILD progression in patients with SSc. We collected data from nailfold capillaroscopy (NFC) in the derivation cohort. A total of 9/98 (9.2\%) patients showed normal-like patterns, 20/98 (20.4\%) patients showed early scleroderma patterns, 33/98 (33.7\%) patients showed active scleroderma patterns and 36/98 (36.7\%) patients showed late scleroderma patterns, respectively. The percentage of active/late scleroderma pattern did not differ significantly among ILD progressors and non-progressors $(72.0 \%$ vs $69.9 \%, \mathrm{p}=0.840)$. After applying multivariate regression, active/late scleroderma pattern in NFC was also not predictive for ILD progression $(\mathrm{p}=0.138)$. Additionally, ' $\mathrm{SpO}$, after $6 \mathrm{MWT}$ ' and 'arthritis ever' were still the only two significant predictors after NFC data were forced in the multivariate regression model.

Unfortunately, we did not have detailed data for exact extent of ILD or oesophageal diameter on HRCT in our cohort. We motivate to include these parameters in further studies.

Wanlong Wu, ${ }^{1,2}$ Suzana Jordan, ${ }^{1}$ Oliver Distler ${ }^{1}$

${ }^{1}$ Department of Rheumatology, University Hospital Zurich, Zurich, Switzerland
${ }^{2}$ Department of Rheumatology, South Campus, Ren Ji Hospital, School of Medicine, Shanghai Jiao Tong University, Shanghai, China

Correspondence to Dr Oliver Distler, Department of Rheumatology, University Hospital Zurich, Zürich 8091, Switzerland; oliver.distler@usz.ch

Handling editor Josef S Smolen

Competing interests None declared.

Patient consent Not required.

Provenance and peer review Commissioned; internally peer reviewed. (c) Author(s) (or their employer(s)) 2018. No commercial re-use. See rights and permissions. Published by BMJ.

\section{A) Check for updates}

To cite Wu W, Jordan S, Distler O. Ann Rheum Dis Epub ahead of print: [please include Day Month Year]. doi:10.1136/annrheumdis-2018-214270

Received 15 October 2018

Revised 29 October 2018

Accepted 30 October 2018

\section{SLinked}

http://dx.doi.org/10.1136/annrheumdis-2018-214256

Ann Rheum Dis 2018;0:1-2. doi:10.1136/annrheumdis-2018-214270

\section{REFERENCES}

1 Wu W, Jordan S, Becker MO, et al. Prediction of progression of interstitial lung disease in patients with systemic sclerosis: the SPAR model. Ann Rheum Dis 2018;77:1326-32.

2 Chattopadhyay A, Dhir V, Sharma S, et al. Will SPAR be useful in the usual patients with scleroderma? Ann Rheum Dis 2018:annrheumdis-2018-214256.

3 Suliman YA, Dobrota R, Huscher D, et al. Brief report: pulmonary function tests: high rate of false-negative results in the early detection and screening of sclerodermarelated interstitial lung disease. Arthritis Rheumatol 2015;67:3256-61.

4 Distler O, Brown KK, Distler JHW, et al. Design of a randomised, placebo-controlled clinical trial of nintedanib in patients with systemic sclerosis-associated interstitial lung disease (SENSCISTM). Clin Exp Rheumatol 2017:35:75-81.

5 Avouac J, Walker UA, Hachulla E, et al. Joint and tendon involvement predict disease progression in systemic sclerosis: a EUSTAR prospective study. Ann Rheum Dis 2016;75:103-9. 